\title{
Optimization-based method of dividing the network development costs
}

\author{
Jerzy Szkutnik • Anna Gawlak
}

Received: 11 July 2010 / Accepted: 22 February 2011 / Published online: 11 March 2011

(C) The Author(s) 2011. This article is published with open access at Springerlink.com

\begin{abstract}
Paper presented the main aspect in efficiency of distribution of network. Losses are inevitably connected with the flow of energy, however not all of them are direct function of the flow. Calculation of losses requires firstly their breakdown according to their source of origin. Technical load losses can be divided into three levels: "real losses i.e. the ones that really exist in the network, justified losses i.e. the ones that may be achieved at efficient operation of the network, optimal losses i.e. the ones, at which level the costs of distribution and supply are the lowest". Calculation of real losses in the distribution network is not sufficient for the evaluation of this network. Comparison of losses, even as percentage of the total energy in the network between different areas e.g. regions doesn't lead to meaningful conclusions. One has to compare real losses with justified or optimal losses. It has to be stressed that unjustified losses i.e. the difference between real losses and justified losses are insignificant, in the range of $2-3 \%$ i.e. approx. $10-15 \%$ of real losses on average. In case of a single region, the difference may be larger. Presentation of the network as a set of elements enables its optimisation as a whole. The cost factors from the optimisation of network development point of view are: (1) deprecation costs of construction of the station, (2) deprecation costs of construction of the line and, (3) costs of losses.
\end{abstract}

Keywords Optimization - Electric networks - Distribution cost $\cdot$ Efficiency

J. Szkutnik ( $\varangle) \cdot$ A. Gawlak

Electrical Power Institute, Technical University of Częstochowa, ul. Dąbrowskiego 69, 42-200 Częstochowa, Poland

e-mail: szkutnik@el.pcz.czest.pl

\section{Introduction}

The main problem in the calculations of distribution network parameters is not so much the great length of such networks, as the lack of information on loads in particular network elements. The large amount of data is manageable by means of computers, but continuous measurements of loads in particular elements, such as line sections, are practically impossible. Instead, it is possible to treat the network as a set of elements.

Means available for investment can be fairly allocated on the basis of the network optimization. The optimization itself, however, is not sufficient and does not lead directly to the method of dividing the financial means. It is also necessary to consider the network transmission capacity defined as the ratio of energy flowing through the network to the percent indicator of loss resulting from the flow $[3,14,19,20]$

$\varepsilon_{p \%}=\frac{E}{\Delta E \%} \cdot 100 \%=\frac{E^{2}}{\Delta E}$

The notion of transmission capacity concerns load loss in the lines of a particular network. The average value of load loss obtained in the last several years in Poland is $85 \%$ for the $110 \mathrm{kV}$ and $94 \%$ for the medium voltage network. In low-voltage networks, the load loss in lines amounts to $45 \%$ of the total loss. Here, the second biggest source of loss is the transformer loss. Therefore, for low-voltage networks, it is necessary to consider the loss in lines and the loss in medium to low voltage transformers jointly. 
Table 1 Transmission capacities in particular area units (RE)

\begin{tabular}{|c|c|c|c|c|c|c|c|c|c|c|c|c|}
\hline & $\begin{array}{l}E_{\mathrm{n}} \\
(\mathrm{MWh})\end{array}$ & $\begin{array}{l}E_{\mathrm{s}} \\
(\mathrm{MWh})\end{array}$ & $\begin{array}{l}\Delta E_{\mathrm{n}} \\
(\%)\end{array}$ & $\begin{array}{l}\Delta E_{\mathrm{s}} \\
(\%)\end{array}$ & $\begin{array}{l}\sigma_{\mathrm{n}} \\
\left(\frac{\mathrm{MWh}}{\mathrm{km}^{2}}\right)\end{array}$ & $\begin{array}{l}\sigma_{\mathrm{s}} \\
\left(\frac{\mathrm{MWh}}{\mathrm{km}^{2}}\right)\end{array}$ & $\left(\frac{\sigma_{\mathrm{n}}}{\sigma_{\mathrm{rn}}}\right)^{\frac{1}{3}} \mathrm{~b}$ & $\left(\frac{\sigma_{\mathrm{s}}}{\sigma_{\mathrm{rs}}}\right)^{\frac{1}{3}}$ & $\begin{array}{l}\Delta E_{\mathrm{rn}} \\
(\%)\end{array}$ & $\begin{array}{l}\Delta E_{\mathrm{rs}} \\
(\%)\end{array}$ & $\begin{array}{l}\varepsilon_{\mathrm{pn}} \\
(\mathrm{GWh})\end{array}$ & $\begin{array}{l}\varepsilon_{\mathrm{ps}} \\
(\mathrm{GWh})\end{array}$ \\
\hline RE1 & 423,740 & 697,465 & 3.34 & 2.71 & 298.62 & 491.52 & 1.045 & 1.277 & 3.49 & 3.46 & 12,142 & 20,158 \\
\hline RE2 & 141,070 & 268,357 & 5.32 & 4.67 & 93.42 & 177.72 & 0.976 & 0.912 & 5.19 & 4.26 & 2,718 & 6,299 \\
\hline RE3 & 229,510 & 425,835 & 4.92 & 2.26 & 140.29 & 260.29 & 0.965 & 1.035 & 4.75 & 2.34 & 4,832 & 18,198 \\
\hline RE4 & 125,970 & 190,180 & 5.61 & 5.47 & 75.56 & 114.07 & 0.950 & 0.784 & 5.33 & 4.29 & 2,363 & 4,433 \\
\hline RE5 & 179,440 & 310,229 & 5.46 & 3.48 & 78.27 & 135.32 & 0.956 & 0.833 & 5.22 & 2.90 & 3,438 & 10,698 \\
\hline RE6 & 191,170 & 403,045 & 4.17 & 4.71 & 156.06 & 329.02 & 1.014 & 1.119 & 4.23 & 5.27 & 4,519 & 7,648 \\
\hline \multicolumn{5}{|c|}{ Average } & 132.40 & $235.40^{\mathrm{a}}$ & & & & & & \\
\hline
\end{tabular}

${ }^{a}$ Average calculated for the whole division

${ }^{\mathrm{b}}$ In the low-voltage network this coefficient is calculated only with respect to load loss in lines

\section{Network transmission capacity}

On the optimum conditions, the loss in the transmission capacity equation is the loss occurring for the minimal cost of energy distribution in a given network. For an area-structure network, the optimum loss is $[4,5]$

$\Delta E_{\mathrm{O} \%}=\sqrt[3]{\frac{W_{\mathrm{s}} k_{\mathrm{FS}} r_{\mathrm{gF}} k_{\mathrm{LZ}} r_{\mathrm{gL}} \cdot 10^{4}}{E k_{\Delta}^{2}}}=k_{\mathrm{o}} E^{-\frac{1}{3}}$

where

$W_{\mathrm{s}}$ the network coefficient

$k_{\mathrm{FS}}$ the variable, power-dependent part of the cost of substation construction, PLN/substation,

$r_{\mathrm{gF}}$ the yearly amortization rate on the cost of substation construction,

$k_{\mathrm{LZ}}$ the variable, cross-section dependent cost of line construction, PLN $/ \mathrm{mm}^{2} \mathrm{~km}$,

$r_{\mathrm{gL}}$ the yearly amortization rate on the line construction cost,

$k_{\Delta}$ the cost of the network loss, PLN/MWh,

$E$ energy, MWh

The coefficient $W_{\mathrm{s}}$, is defined as

$W_{\mathrm{s}}=\frac{\chi^{2} A\left(2 t_{\mathrm{s}}+1\right)}{67 t_{\mathrm{s}} U_{\mathrm{r}}^{2} \cos ^{2} \varphi_{\mathrm{r}} k_{\mathrm{rL}} \delta_{\mathrm{s}}}$

where

A area, $\mathrm{km}^{2}$,

$\chi \quad$ the coefficient of area idealization,

$t_{\mathrm{s}} \quad$ the relative time of load peak,

$U_{\mathrm{r}} \quad$ average yearly voltage at the clamps, $\mathrm{kV}$,

$\cos \varphi_{\mathrm{r}}$ the average yearly power coefficient,

$\delta_{\mathrm{s}} \quad$ the coefficient of cross-section utilization,

$k_{\mathrm{rL}} \quad$ the coefficient of line reserves. substituting (3) into Eq. (2)

$\Delta E_{\mathrm{o}} \%=k_{\mathrm{o}} \sigma^{-\frac{1}{3}}$

where $\sigma=E / A \quad\left(\mathrm{MWh} / \mathrm{km}^{2}\right)$ is the density of energy load.

Since the optimum loss is proportional to the third root of area load, the same proportion was preserved in obtaining the loss per average load in an area unit. The average load in an area unit is not a straightforward issue. There is a significant difference in load between urban areas and other areas. At the same time, the percent indicators of loss are reversely dependent on area loads but this relationship is not proportional.

The problem lies in the fact that the relationships are different for the area model of the network and for the linear model applied to the low-voltage network. In the case of a rural low-voltage network, it is difficult to ascribe a particular area to a given network. Additionally, the loss in the medium/low-voltage transformers has to be considered and it is a considerable portion of total loss in this kind of network. In spite of that, it is undoubtedly necessary to consider the differences in the area loads when comparing area units. Because of that, the average area load was calculated for area units. The average area load, which is not equal to the average value of area units, was used as reference for percentage loss, calculated proportionally to the third root. In this way an amended percent loss indicator was obtained, which is now valid for all the types of networks. With this indicator, the transmission capacity was calculated for low- and medium-voltage networks in a distribution company. The results can be seen in Table 1.

The transmission capacity for the $110 \mathrm{kV}$ network was obtained separately

$\varepsilon_{\mathrm{p} 110}=\frac{4,963.920 \mathrm{GWh}}{2.4847 \%} 100 \%=199,779 \mathrm{GWh}$ 
The differences between transmission capacities for medium and low voltages are notable, especially in urban areas. In comparison to the $110 \mathrm{kV}$ network, however, they are relatively insignificant as the capacity is about 40 times lower. It results from the difference in the voltages and its influence on the load loss, being the major part of total loss. Such differences do not occur between the medium- and low-voltage networks because load loss in low-voltage networks is not the major portion of total loss. The differences will be affected by the proportion between current loss and voltage loss.

The magnitude of the transmission capacity cannot be treated as the only parameter for assessing the network operation. It is necessary to compare the existing capacity to the optimum capacity and therefore to find an optimum loss indicator, i.e. the indicator of loss corresponding to the minimal energy distribution cost.

\section{Network optimization}

\subsection{Introductory remarks}

The theoretical foundations of network optimization are described in [2, 6, 7]. Some coefficients, especially cost coefficients are difficult to establish, but some solutions have to be found.

The optimization of the $110 \mathrm{kV}$ network and medium-voltage network is based on the area-structure network model. For the low-voltage network, a linear-structure model with the medium-/low-voltage transformers is more appropriate.

\subsection{Optimization equations}

The power network can be divided into

1. Networks covering and feeding a specific area, referred to as area-structure networks and including low-voltage urban networks, all medium-voltage networks, $110 \mathrm{kV}$ networks.

2. Networks which do not cover a specific area, referred to as linear-structure networks, and including rural lowvoltage networks.

Treating the network as a set of elements makes it possible to optimize it as a whole. Such optimization is of limited range, however, since it concerns only a number of substations feeding a network and the average cross-section of lines constituting the network. The loss cannot be disregarded in optimizing the network because the loss is a part of costs. Since the network optimization has to be based on the amount of energy flowing through the network, only the loss associ- ated with the energy flow is to be considered as an element of costs. Other kinds of loss, such as voltage loss, or accounting loss can be disregarded as not affecting the optimization results.

Other elements of costs which are to be taken into account on the network development optimization are: (1) amortization on the cost of building substations, (2) amortization on the cost of building lines and (3) cost of loss [11, 12]. The basic cost equation is

$$
\begin{aligned}
K= & F\left(k_{\mathrm{FS}}+\bar{S} \cdot k_{\mathrm{FZ}}\right) r_{\mathrm{gF}} \\
& +L\left(k_{\mathrm{LS}}+s_{\mathrm{hr}} k_{\mathrm{LZ}}\right) r_{\mathrm{gL}}+\Delta E_{\mathrm{o}} \cdot k_{\Delta}
\end{aligned}
$$

where

$\begin{array}{ll}F & \text { the number of substations } \\ \bar{S} & \text { the average power of a substation, MVA } \\ k_{\mathrm{FZ}} & \text { the variable, power-dependent cost of } \\ & \text { building a substation PLN/station MVA } \\ L & \text { the length of the distribution lines, } \mathrm{km} \\ k_{\mathrm{LS}} & \text { the constant cost of the lines building PLN/ km a } \\ s_{\mathrm{hr}} & \text { the line commercial cross-section, } \mathrm{mm}^{2} \\ \Delta E_{\mathrm{O}} & \text { the energy loss in the network, MWh/a } \\ k_{\Delta} & \text { the cost of the energy loss, PLN/MWh a }\end{array}$

On the basis of Eq. (5) the optimum value of the parameters, such as cross-section, number of substations, and load loss level are determined. The $110 \mathrm{kV}$ and the medium-voltage networks are area-structure networks, so the calculations are made on the basis of [8-10]

- The optimum number of substations

$$
F_{\mathrm{O}}=\sqrt[3]{\frac{a_{\mathrm{S}} E^{2} W_{\mathrm{S}} k_{\Delta} k_{\mathrm{Lz}} r_{\mathrm{gL}}}{100\left(k_{\mathrm{Fs}} r_{\mathrm{gF}}\right)^{2}}}
$$

- The optimum cross-section

$s_{\mathrm{hro}}=\frac{1}{L} \sqrt[3]{\frac{a_{\mathrm{S}} E^{2} W_{\mathrm{S}} k_{\Delta} k_{\mathrm{FS}} r_{\mathrm{gF}}}{100\left(k_{\mathrm{LZ}} r_{\mathrm{gL}}\right)^{2}}}+b_{\mathrm{s}}$

where $a_{\mathrm{s}}, b_{\mathrm{s}}$ - are the indicators for graded cross-sections assumed as $a_{\mathrm{s}}=0.305, b_{\mathrm{s}}=24.3$

- The optimum loss indicator is

$$
\Delta E_{\mathrm{o}} \%=\sqrt[3]{\frac{a_{\mathrm{s}} W_{\mathrm{s}} k_{\mathrm{FS}} r_{\mathrm{gF}} k_{\mathrm{LZ}} r_{\mathrm{gL}} \cdot 10^{4}}{E k_{\Delta}^{2}}}
$$


Table 2 Output data for the optimization of the low- and medium voltage networks

\begin{tabular}{llllllc}
\hline & SD & RE1 & RE2 & RE3 & RE4 & RE5 \\
\hline$A\left[\mathrm{~km}^{2}\right]$ & 9,634 & 1,419 & 1,636 & 1,225 & 2,293 & 1,667 \\
$L_{\mathrm{nn}}[\mathrm{km}]$ & 15,665 & 13,664 & 2,516 & 1,483 & 3,608 & 2,950 \\
$L_{\mathrm{nn}}[\mathrm{km}]$ & 3,242 & 1,140 & 656 & 585 & 401 & 1,510 \\
$L_{\mathrm{SN}}[\mathrm{km}]$ & 9,798 & 1,147 & 1,556 & 936 & 2,072 & 1,601 \\
$L_{\mathrm{SNk}}[\mathrm{km}]$ & 1,118 & 428 & 232 & 219 & 104 & 50 \\
$E_{\mathrm{nn}}[\mathrm{MWh}]$ & $1,103,886$ & 359,040 & 201,327 & 162,092 & 159,218 & 103,207 \\
$E_{\mathrm{SN}}[\mathrm{MWh}]$ & $2,193,177$ & 697,465 & 425,835 & 403,095 & 310,229 & 1,508 \\
$F_{\mathrm{nn}}[\mathrm{number}]$ & 40 & 10 & 9 & 4 & 5 & 190,180 \\
$F_{\mathrm{SN}}[$ number $]$ & 8,848 & 1,523 & 1,676 & 1,017 & 1,797 & 26,002 \\
\hline
\end{tabular}

Table 3 Optimum parameters for the medium-voltage network

\begin{tabular}{llllll}
\hline & Unit & $W_{\mathrm{s}}$ & $F_{\mathrm{o}}$ & $s_{\text {hro }}$ & $\Delta E_{\mathrm{o}} \%$ \\
\hline 1 & RE1 & 16.9 & 7 & 63.5 & 3.03 \\
2 & RE2 & 2.65 & 2 & 49.5 & 3.25 \\
3 & RE3 & 2.87 & 6 & 48.2 & 3.37 \\
4 & RE4 & 2.92 & 1 & 44.1 & 3.59 \\
5 & RE5 & 4.02 & 3 & 47.6 & 3.47 \\
6 & RE6 & 2.15 & 2 & 45.2 & 2.91 \\
7 & Average & 5.25 & 3.5 & 49.7 & 3.27 \\
\hline
\end{tabular}

In Table 2, the output data are shown for the optimization of the low- and medium-voltage networks for the particular area units (RE). The data contained in Table 2 and the data on the cost of the network construction and on other technical and financial parameters were used for calculating the optimum parameters, shown in Table 3. The optimum loss indicator for the $110 \mathrm{kV}$ network is $\Delta E_{\mathrm{o}} 110 \mathrm{kV}=1.14 \%$, and this value is only marginally lower from the value representing the real loss $(1.55 \%)$ in this company.

\subsection{Optimization of the linear-structure network}

For the linear-structure network, the equation representing the energy distribution cost with the cost of transformer loss is $[13,15]$

$$
\begin{aligned}
K_{\mathrm{r}}= & F\left(k_{\mathrm{FS}}+\bar{S} k_{\mathrm{FZ}}\right) r_{\mathrm{gF}} \\
& +L\left(k_{\mathrm{LS}}+s_{\mathrm{hr}} k_{\mathrm{LZ}}\right) r_{\mathrm{gL}}+\frac{E^{2} L W_{\mathrm{LN}}}{100 F^{2} s_{\mathrm{hr}}} \cdot k_{\Delta} \\
& +F^{\frac{1}{4}}\left(\frac{E}{T_{\mathrm{S}} \cos \varphi_{\mathrm{s}} \beta_{\mathrm{s}}}\right)^{\frac{3}{4}} k_{\mathrm{r}}\left(a_{\mathrm{u}} \beta_{\mathrm{s}}^{2} k_{\mathrm{T}} \tau k_{\Delta \mathrm{T}}+a_{\mathrm{j}} T_{\mathrm{r}} k_{\Delta \mathrm{j}}\right)
\end{aligned}
$$

where:

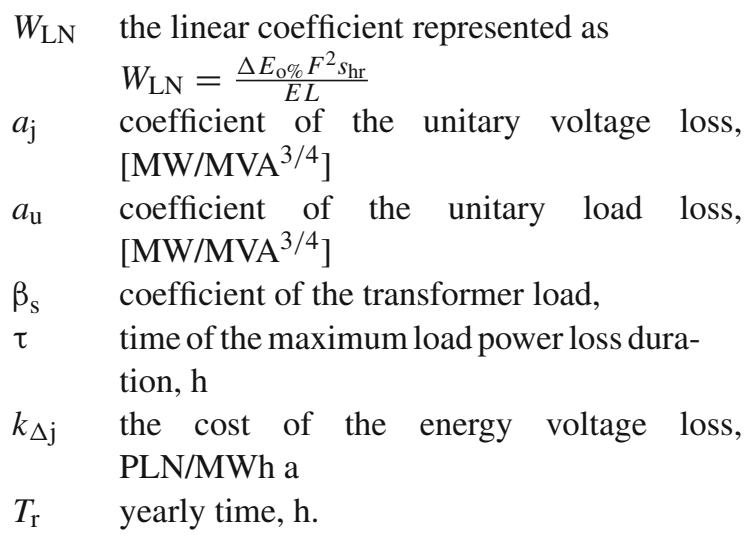

After calculating the first derivative with respect to the number of stations and the cross-section, equating it with zero and solving the following is obtained

$$
\begin{aligned}
& k_{\mathrm{FS}} r_{\mathrm{gF}}-\frac{2 E L W_{\mathrm{LN}} k_{\Delta}}{10 F^{2} \sqrt{\frac{W_{\mathrm{LN}} k_{\Delta}}{k_{\mathrm{LZ}} r_{\mathrm{gL}}}}} \\
& +\frac{\left(\frac{E}{T_{\mathrm{s}} \cos \varphi_{\mathrm{s}} \beta_{\mathrm{s}}}\right)^{\frac{3}{4}} k_{\mathrm{r}}\left(a_{\mathrm{u}} \beta_{\mathrm{s}}^{2} k_{\mathrm{T}} \tau k_{\Delta \mathrm{T}}+a_{\mathrm{j}} T_{\mathrm{r}} k_{\Delta \mathrm{j}}\right)}{4 F^{\frac{3}{4}}}=0
\end{aligned}
$$

The equation above does not have an analytic solution with respect to the number of substations $F$. It can be solved by means of the Chebyshev equations.

- The optimum number of substations will be then 


$$
\begin{aligned}
F_{\mathrm{o}}= & \frac{\sqrt{0.104\left(\frac{E}{T_{\mathrm{s}} \cos \varphi_{\mathrm{s}} \beta_{\mathrm{s}}}\right)^{\frac{6}{4}} \lambda^{2}+\left[4 k_{\mathrm{FS}} r_{\mathrm{gF}}+0.052\left(\frac{E}{T_{\mathrm{s}} \cos \varphi_{\mathrm{s}} \beta_{\mathrm{s}}}\right)^{\frac{3}{4}} \lambda\right] \cdot\left[0.2 E L \sqrt{W_{\mathrm{LN}} k_{\Delta} k_{\mathrm{LZ}} r_{\mathrm{gL}}}+0.071\left(\frac{E}{T_{\mathrm{s}} \cos \varphi_{\mathrm{s}} \beta_{\mathrm{s}}}\right)^{\frac{3}{4}} \lambda\right]}}{2 k_{\mathrm{FS}} r_{\mathrm{gF}}+0.026\left(\frac{E}{T_{\mathrm{s}} \cos \varphi_{\mathrm{s}} \beta_{\mathrm{s}}}\right)^{\frac{3}{4}} \lambda}+ \\
& -\frac{0.323\left(\frac{E}{T_{\mathrm{s}} \cos \varphi_{\mathrm{s}} \beta_{\mathrm{s}}}\right)^{\frac{3}{4}} \lambda}{2 k_{\mathrm{FS}} r_{\mathrm{gF}}+0.026\left(\frac{E}{T_{\mathrm{s}} \cos \varphi_{\mathrm{s}} \beta_{\mathrm{s}}}\right)^{\frac{3}{4}} \lambda} \\
\lambda= & k_{\mathrm{r}} a_{\mathrm{j}} T_{\mathrm{r}} k_{\Delta \mathrm{j}}+k_{\mathrm{r}} a_{\mathrm{u}} \beta_{\mathrm{s}}^{2} k_{\mathrm{T}} \tau k_{\Delta \mathrm{T}}
\end{aligned}
$$

- The optimum cross-section

$$
s_{\mathrm{hro}}=\sqrt{\frac{E^{2} W_{\mathrm{LN}} k_{\Delta}}{100 F^{2} k_{\mathrm{LZ}} r_{\mathrm{gL}}}}
$$

- The optimum loss indicator

$$
\Delta E_{\mathrm{o} \%}=\frac{W_{\mathrm{LN}} E L}{F_{\mathrm{o}}^{2} s_{\mathrm{hro}}}
$$

Equation (10) can also be solved numerically. In this equation the optimum transformer load coefficient $\beta_{\mathrm{s}}$ appears, whose value is not known when the optimization is carried out.

The equation representing the cost of energy loss in a group of transformers is

$$
K_{\Delta \mathrm{T}}=F^{1 / 4}\left(\frac{E}{T_{\mathrm{S}} \cos \varphi_{\mathrm{s}} \beta_{\mathrm{s}}}\right)^{3 / 4} k_{\mathrm{r}}\left(a_{\mathrm{u}} \beta_{\mathrm{s}}^{2} k_{\mathrm{T}} \tau k_{\Delta}+a_{\mathrm{j}} T_{\mathrm{r}} k_{\Delta \mathrm{j}}\right)
$$

First, it is necessary to obtain the derivative of the cost with respect to the transformer load ratio $\beta_{s}$ from Eq. (13) and equate it with zero. In this way the formula for the optimum transformer load coefficient is arrived at

$$
\beta_{\mathrm{o}}=\sqrt{\frac{3\left(k_{\mathrm{Fz}} r_{\mathrm{gF}}+a_{\mathrm{j}} k_{\mathrm{r}} T_{\mathrm{r}} k_{\Delta \mathrm{j}}\right)}{5 k_{\mathrm{r}} a_{\mathrm{u}} k_{\mathrm{T}} \tau k_{\Delta}}}
$$

When the cost of building a substation is taken into consideration, Eq. (14) becomes

$$
\begin{aligned}
K= & F\left(k_{\mathrm{Fs}}+\left(\frac{E}{F T_{\mathrm{s}} \cos \varphi_{\mathrm{s}} \beta_{\mathrm{s}}}\right) k_{\mathrm{Fz}}\right) r_{\mathrm{gF}} \\
& +F^{1 / 4}\left(\frac{E}{T_{\mathrm{s}} \cos \varphi_{\mathrm{s}} \beta_{\mathrm{s}}}\right)^{3 / 4} k_{\mathrm{r}}\left(a_{\mathrm{u}} \beta_{\mathrm{s}}^{2} k_{\mathrm{T}} \tau k_{\Delta}+a_{\mathrm{j}} T_{\mathrm{r}} k_{\Delta \mathrm{j}}\right)
\end{aligned}
$$

Differentiating Eq. (15) with respect to the transformer load coefficient yields

$$
\begin{aligned}
\frac{d K}{d \beta_{\mathrm{s}}}= & -\left(\frac{E}{T_{\mathrm{S}} \cos \varphi_{\mathrm{s}}}\right) k_{\mathrm{Fz}} r_{\mathrm{gF}} \beta_{\mathrm{s}}^{-2} \\
& +\frac{5}{4} \cdot F^{1 / 4}\left(\frac{E}{T_{\mathrm{S}} \cos \varphi_{\mathrm{s}}}\right) k_{\mathrm{r}} a_{\mathrm{u}} k_{\mathrm{T}} \tau k_{\Delta} \beta_{\mathrm{s}}^{1 / 4} \\
& -\frac{3}{4} \cdot F^{1 / 4}\left(\frac{E}{T_{\mathrm{s}} \cos \varphi_{\mathrm{s}}}\right) a_{\mathrm{j}} k_{\mathrm{r}} T_{\mathrm{r}} k_{\Delta \mathrm{j}} \beta_{\mathrm{s}}^{-7 / 4}
\end{aligned}
$$

Substituting for $\beta_{\mathrm{s}}^{-1 / 4}=x ; a=\left(\frac{E}{T_{\mathrm{S}} \cos \varphi_{\mathrm{s}}}\right) k_{\mathrm{FZ}} r_{\mathrm{gF}}$;

$b=\frac{5}{4} F^{1 / 4}\left(\frac{E}{T_{\mathrm{S}} \cos \varphi_{\mathrm{s}}}\right)^{3 / 4} k_{\mathrm{r}} a_{\mathrm{u}} k_{\mathrm{T}} \tau k_{\Delta} ;$

$c=\frac{3}{4} F^{3 / 4}\left(\frac{E}{T_{\mathrm{S}} \cos \varphi_{\mathrm{s}}}\right)^{3 / 4} k_{\mathrm{r}} a_{\mathrm{j}} T_{\mathrm{r}} k_{\Delta \mathrm{j}}$

the above equation can be brought to

$-a x^{9}+b-c x^{8}=0$

The equation does not have an analytic solution but it can be solved by means of iterative methods, such as the Newton tangent method. It can also be solved approximately with the following simplifying assumption

$x^{8}(a x+c)=b$

The value $\beta_{\text {opt }}$ is in the interval $0.6 \div 1$; the value of $x$ is about 1 . Thus, $x^{8}(a+c)=b$. Then, the formula for the optimum load transformer coefficient is

$\beta_{\mathrm{so}}=\sqrt{\frac{3 F^{1 / 4} k_{\mathrm{r}} a_{\mathrm{j}} T_{\mathrm{r}} k_{\Delta \mathrm{j}}+4\left(\frac{E}{T_{\mathrm{s}} \cos \varphi_{\mathrm{s}}}\right)^{1 / 4} k_{\mathrm{FZ}} r_{\mathrm{gF}}}{5 F^{1 / 4} k_{\mathrm{r}} a_{\mathrm{u}} p_{\mathrm{RT}} \tau k_{\Delta}}}$

The optimum parameters calculated are shown in Table 4.

The optimum loss given in Table 4 concerns the lines and transformers with the optimum number of substations and the optimum transformer load. 
Table 4 Optimum parameters in the low-voltage network

\begin{tabular}{rlllrll}
\hline & Unit & $W_{\mathrm{LN}}$ & \multicolumn{1}{l}{$\beta_{\mathrm{s}}$} & \multicolumn{1}{c}{$F_{\mathrm{o}}$} & \multicolumn{1}{l}{$s_{\text {hro }}$} & $\Delta E_{\mathrm{o} \%}$ \\
\hline 1 & RE1 & 0.1984 & 0.81 & 716 & 70.15 & 5.08 \\
2 & RE2 & 0.4655 & 0.81 & 951 & 31.16 & 8.97 \\
3 & RE3 & 0.4370 & 0.80 & 1,084 & 41.87 & 7.55 \\
4 & RE4 & 0.5413 & 0.79 & 1,038 & 27.95 & 9.45 \\
5 & RE5 & 0.4422 & 0.79 & 1,257 & 29.32 & 8.81 \\
6 & RE6 & 0.3821 & 0.79 & 688 & 49.71 & 6.84 \\
\hline
\end{tabular}

\section{Comparison of the transmission capacity}

On the basis of the data and formulas given above the per cent energy losses and transmission capacities of the particular networks were obtained. The networks were divided

a. According to the administrative division into area units

b. According to the voltages into low and medium

c. The $110 \mathrm{kV}$ network was treated separately because it has to be considered holistically at the level of the distribution company.

Taking into account that the transmission capacity is always expressed in $(\mathrm{GWh} / \%)$, and the differences occurring between urban and rural areas are small in comparison to the difference between the $110 \mathrm{kV}$ and the lower voltages the distinction between urban and rural areas will be disregarded in further considerations.

In Table 5, the percent energy losses, both optimum and real, are shown for the area units and voltages. The energy loss is equivalent to the load loss in the medium-voltage and $110 \mathrm{kV}$ networks. The data concerning the latter are valid for the whole distribution company. For the low-voltage network, the loss is equivalent to the load loss in the lines and the total loss in the medium-/low-voltage transformers, both for the real loss and the optimum loss.
Further, the transmission capacities, i.e. the ratios of energy input to the network to the percentage loss coefficients are compared. In the next columns, one can see the differences between the optimum and real transmission capacities. The negative value means that the real capacity is higher than the optimum capacity. It follows from Table 5 that the condition of the low-voltage network is somewhat better than the optimum-all the values are negative. In the mediumvoltage networks, a greater variety can be seen, depending on the area unit.

It is difficult to point to one definite explanation of the fact that all the low-voltage networks are better than the optimum. In the last 15-20 years, the consumption of energy by receivers fed from the low-voltage network has been kept at more or less the same level, so the reason cannot be associated with the drop in such energy consumption. One could seek explanation in the tendency to invest substantial amount of money into the low-voltage networks, or in the proportion between the cost of investment and the cost of energy. It may well be the case that both of the factors play a role here. It is also interesting to note that the change in the proportion of costs, and more precisely increase in the investment cost is not observed in the medium and $110 \mathrm{kV}$ networks and only in the low-voltage networks. It will obviously affect the distribution of the investment means.

In order to find a non-ambiguous basis for the distribution of the means, it is necessary to standardize the results by adding to all the differences between the optimum $\backslash$ and real transmission capacities the value corresponding to the lowest value of the difference. Such lowest value can be found in the medium-voltage network of Unit $3-5562 \mathrm{GWh}$, When this value is added with the positive sign, the overview is obtained as in Table 5.

The percent investment expenditure shares are determined on the basis of the difference between the optimum and the real transmission capacity of the network. The distribution of the means is dominated by the $110 \mathrm{kV}$ network, as a result of the amount of energy flowing. Even a small improvement in the efficiency of this network results in significant savings

Table 5 Transmission capacities

\begin{tabular}{|c|c|c|c|c|c|c|c|c|c|c|}
\hline \multirow[t]{2}{*}{ Rejon } & \multicolumn{2}{|c|}{$\Delta E_{\mathrm{nr} \%}$} & \multicolumn{2}{|c|}{$\Delta E_{\mathrm{SN}} \%$} & \multicolumn{2}{|c|}{$\varepsilon_{\mathrm{pn}}(\mathrm{GWh})$} & \multicolumn{2}{|c|}{$\varepsilon_{\mathrm{ps}}(\mathrm{GWh})$} & \multicolumn{2}{|c|}{$\Delta \varepsilon=\varepsilon_{\mathrm{opt}}-\varepsilon_{\mathrm{rzecz}}$} \\
\hline & Real & Opt. & Real & Opt. & Real & Opt. & Real & Opt. & Low voltage & Medium voltage \\
\hline RE1 & 3.49 & 5.09 & 3.46 & 3.03 & 121,42 & 8,325 & 201.58 & 230.19 & $-3,817$ & 2,861 \\
\hline RE2 & 5.19 & 8.91 & 4.26 & 3.25 & 2,718 & 1,583 & 62.99 & 82.57 & $-1,135$ & 1,958 \\
\hline RE3 & 4.75 & 7.52 & 2.34 & 3.37 & 4,832 & 3,052 & 181.98 & 126.36 & $-1,780$ & $-5,562$ \\
\hline RE4 & 5.33 & 9.30 & 4.29 & 3.59 & 2,363 & 1,355 & 44.33 & 52.97 & $-1,008$ & 864 \\
\hline RE5 & 5.22 & 8.80 & 2.90 & 3.47 & 3,438 & 2,039 & 106.98 & 89.40 & $-1,399$ & $-1,758$ \\
\hline RE6 & 4.23 & 6.78 & 5.27 & 2.91 & 4,519 & 2,820 & 76.48 & 138.50 & $-1,699$ & 6,202 \\
\hline SD & 4.70 & 7.73 & 3.75 & 3.27 & 5,002 & 3,246 & 112.39 & 120.00 & $-1,806$ & 761 \\
\hline
\end{tabular}


Table 6 Investment distribution

\begin{tabular}{|c|c|c|c|c|c|c|}
\hline & \multirow[t]{2}{*}{ Unit } & \multicolumn{2}{|c|}{ Network (GWh) } & \multicolumn{3}{|l|}{ Share $(\%)$} \\
\hline & & Low voltage & Medium & Low voltage & Medium & Low + medium \\
\hline 1 & RE1 & 1,745 & 8,423 & 1.23 & 5.94 & 7.17 \\
\hline 2 & RE2 & 4,427 & 7,520 & 3.12 & 5.31 & 8.43 \\
\hline 3 & RE3 & 3,782 & 0 & 2.67 & 0.00 & 2.67 \\
\hline 4 & RE4 & 4,554 & 6,426 & 3.21 & 4.53 & 7.74 \\
\hline 5 & RE5 & 4,163 & 3,804 & 2.94 & 2.68 & 5.62 \\
\hline \multirow[t]{2}{*}{6} & RE6 & 3,863 & 11,702 & 2.73 & 8.26 & 10.99 \\
\hline & $110 \mathrm{kV}$ & \multicolumn{2}{|c|}{81,290} & \multicolumn{3}{|c|}{57.37} \\
\hline
\end{tabular}

Table 7 The investment distribution in the low- and medium-voltage networks

\begin{tabular}{lllll}
\hline \multirow{2}{*}{ Unit } & \multicolumn{2}{l}{ Share $(\%)$} & \\
\cline { 3 - 5 } & & Low voltage & Medium & Low + medium voltage \\
\hline 1 & RE1 & 2.89 & 13.94 & 16.83 \\
2 & RE2 & 7.32 & 12.46 & 19.78 \\
3 & RE3 & 6.26 & 0.00 & 6.26 \\
4 & RE4 & 7.53 & 10.63 & 18.16 \\
5 & RE5 & 6.90 & 6.28 & 13.19 \\
6 & RE6 & 6.41 & 19.38 & 25.79 \\
& Total & 37.31 & 62.96 & 100.00
\end{tabular}

in terms of absolute loss.

$$
\begin{aligned}
& \Delta E_{\mathrm{oo}}=1.14 \% \quad \varepsilon_{\mathrm{po}}=435,432 \mathrm{GWh} \\
& \Delta E_{\mathrm{o}}=1.38 \% \quad \varepsilon_{\mathrm{pr}}=359,704 \mathrm{GWh} \quad \Delta \varepsilon_{\mathrm{p}}=75,718 \mathrm{GWh}
\end{aligned}
$$

Since the $110 \mathrm{kV}$ network is dominant in the investment share distribution, it may appear that the differences in the means assigned to the lower-voltages networks are small. If one looks at the distribution of investment between the low- and medium-voltage networks in particular area units, the differences are significant. The investment is at the similar level for the low voltage networks, with the exception of RE1, and varies from zero to almost $20 \%$ in the medium-voltage network. It has to be noted that if the distribution of the investment did not cover the $110 \mathrm{kV}$ network, the shares within the lowand medium-voltage networks, see Table 6 , would remain the same because they would be based on the same differences between the optimum and real transmission capacities.

There is one more aspect of the problem, namely the cost of making a consumer connection, which is not subject to any systematic treatment. It is difficult to predict whether the investment means allocated on the basis of the transmission capacity will be sufficient to cover the cost of the connection. Alternatively, a distribution company could retain some means for this purpose before dividing the means among the networks.

\section{Financing the consumer connections}

According to the regulations, the energy distribution company is obliged to connect new consumers to the network or to increase the capacity of the existing connection, regardless of how the cost of the new connection is ultimately settled [1, 16-18]. Thus, the distribution unit (area unit, company), must be capable of financing the necessary cost of materials and labour.

The following issues related to financing new consumer connections deserve attention:

a. The means required may be high as compared to the cost of network development and modernization.

b. The cost of new connections is not associated with the difference between the optimum and real values of the network transmission capacity.

c. The cost will vary depending on the network voltage so it has to be considered separately for each case.

\section{$5.1110 \mathrm{kV}$ network}

A consumer fed from the $110 \mathrm{kV}$ network is not a retail consumer. Such consumer's application for the connection is submitted well in advance and the method of connection and its financing is usually subject to negotiations. It has to be remembered that the energy supplier will profit from gaining such a customer in two ways: by increasing energy sales and by increasing the network transmission capacity $(110 \mathrm{kV})$.

As was mentioned, plans to connect major $110 \mathrm{kV}$ consumers are made in advance so there is enough time to allow for the availability of means, which can be allocated for this purpose out of the total amount of means intended for the network development and modernization.

Let the symbol $\sum N_{\mathrm{r}}$ stand for the total network development means and $N_{\mathrm{p} 110}$ for the new connection means. Then the amount of investment means left for the actual development and modernization of the network is 
$N_{\mathrm{r}}=\sum N_{\mathrm{r}}-N_{\mathrm{p} 110}$

It will be further divided according with the needs determined by the network transmission capacity, including the $110 \mathrm{kV}$ network. The fact that connecting a new consumer will affect the $110 \mathrm{kV}$ network transmission capacity cannot be considered in the calculations until the new connection is completed.

\subsection{Medium-voltage network}

In medium-voltage networks, similarly to low-voltage networks, things look different. The request of a new customer for a connection may not be known in advance, yet it has to be fulfilled.

Connecting each new consumer affects the network transmission capacity. The capacity may increase or decrease depending on the solution adopted for the connection. If the new connection does change the network transmission capacity, then there is a good reason to finance the new connection from the means available for improving the network transmission capacity. A problem may appear, however, since as was mentioned above, the investment on the network development depends on the difference between the optimum and real transmission capacity. Should it happen that no such difference occurs as in the case of an optimum network, no investment expenditure will be allowed for to finance network development. Yet, it will be necessary to provide some means for financing new connections. The amount of such investment expenditure should be based on the real transmission capacity, since the greater the transmission capacity, the greater the number of consumers, and consequently the greater the number of devices (lower loss), and potentially, higher needs concerning new consumer connections.

The relationship between the network real transmission capacity and the investment expenditure on new consumer connections has been examined. The study was not very extensive because distribution companies are generally unwilling to reveal data on this kind of investment. The results led to establishing correlation coefficients $r_{\mathrm{xy}}=0.7676$ with four degrees of freedom. This entails a correlation relationship at the level of $90 \%$ of significance, which may be considered insufficient, since the usual standard in technology is $95 \%$, which would be attained if the correlation coefficient was equal to or higher than $0.811>0.768$. Since in this case, however, the regression equation will not be applied, it can be assumed that the correlation between the real transmission capacity and the investment expenditure has been sufficiently proven, and consequently, that the financing of new connections is associated with the transmission capacity.

It is more complicated to decide about the amount of expenditure needed. As far as possible, the data on the amount of investment spent on connecting new consumers as a ratio of the total investment expenditure have also been analysed. The share of investment in question varies from low- to medium-voltage networks and from one area unit or company to another. For example, in medium-voltage networks investment on new connections is about $30-40 \%$ of the total investment expenditure.

As was mentioned, there is no need for a distribution company to provide a full means for financing new connections. The company, or its area units will be able to cover part of the cost from the basic share of investment expenditure calculated on the basis of the difference between the real and optimum network transmission capacity. The separate provisions to cover the cost of connections are necessary 'just in case', if the basic share turns out to be insufficient. In this paper it is assumed that the extra expenditure is at the level of $50 \%$ of the total cost of new connections, so for the medium-voltage network it is $35 / 2=17.5 \%$ of the total network modernization and development cost. The possibility should also be allowed for of adjusting the actual amount by $\pm 10 \%$ in the calculation program. Such adjustment can be made by the person performing the calculations. It is, however, vital that the range of the adjustment is the same for all area units.

\subsection{Low-voltage network}

The only difference with respect to the medium-voltage network is that here the investment expenditure on new consumer connections have to be relatively higher as compared to total expenditure in all low-voltage network. They are usually about $60-80 \%$ of the total investment expenditure. Analogously to the medium-voltage network, it is assumed that it suffices to provide half of the expenditure necessary, which will amount to $35 \%$ of the total investment cost. The $\pm 10 \%$ adjustment is also allowed for.

\subsection{Investment expenditure distribution — a summary}

The following procedure is assumed:

1. The total investment expenditure $\sum N_{\mathrm{r}}$ on the network development and modernization is established.

2. The cost of new consumer connections in the $110 \mathrm{kV}$ network during the period considered is subtracted

$N_{\mathrm{r}}=\sum N_{\mathrm{r}}-N_{\mathrm{p} 110}$

3. The results of loss calculations performed by the software STRATY are the basis of obtaining the real transmission capacity $\varepsilon_{\mathrm{p}}$ for all the networks in an area. In the case of the $110 \mathrm{kV}$ network, the transmission capacity 
is calculated only for the whole distribution company and in the case of medium- and low-voltage networks also for the particular area units. For the $110 \mathrm{kV}$ and medium-voltage networks only the load loss in lines are considered. For the low-voltage network, the percentage loss for the sum of the load loss in lines and the total loss in medium/low voltage transformers has to be taken into account. The percentage loss is calculated with respect to the total energy input in a network. The following parameters are thereby obtained

- $\varepsilon_{\mathrm{p} 110}$ - the $110 \mathrm{kV}$ network transmission capacity,

- $\varepsilon_{\mathrm{pSN}}=\sum^{\mathrm{i}} \varepsilon_{\mathrm{pSNi}}$ - the sum of transmission capacities of the medium-voltage area units- $\mathrm{i}-$ the numbers of area units

- $\varepsilon_{\mathrm{pnN}}=\sum^{\mathrm{i}} \varepsilon_{\mathrm{pnNi}}$ - the sum of transmission capacities of the low voltage are units-i-the numbers of area units

4. On the basis of the formulae presented in Sect. 3 the optimization of the low- voltage, medium-voltage, and $110 \mathrm{kV}$ networks is performed. The optimization concerns calculating the optimum loss, which for the medium-voltage and $110 \mathrm{kV}$ networks is the load loss in lines, whereas for the low-voltage network, the load loss in lines and the medium-/low-voltage transformer loss are optimized jointly.

5. The optimum transmission capacity for the particular networks, by voltages and by area units is obtained. For the $110 \mathrm{kV}$ network, the transmission capacity is calculated for the whole distribution company. The following parameters are obtained:

- $\varepsilon_{\text {po110 }}$ - the optimum transmission capacity for the $110 \mathrm{kV}$ network,

- $\varepsilon_{\mathrm{poSN}}=\sum^{\mathrm{i}} \varepsilon_{\mathrm{poSNi}}$-the sum of the optimum transmission capacities of the medium-voltage network area units- $\mathrm{i}-$ the numbers of area units

- $\varepsilon_{\text {ponN }}=\sum^{\mathrm{i}} \varepsilon_{\text {ponNi }}$-the sum of the optimum transmission capacities of the low-voltage network area units- $\mathrm{i}$ - the numbers of area units

The optimum transmission capacity $\varepsilon_{\mathrm{po}}$ is obtained by dividing the energy input in a network by the optimum percentage loss indicator.

6. The differences between the optimum and real transmission capacities for the particular networks $\varepsilon_{\text {poi }}-\varepsilon_{\mathrm{pi}}$ $=\Delta \varepsilon_{\mathrm{pi}}$ are determined (Table 5). The same is done for the $110 \mathrm{kV}$ network at the level of a distribution company.

7. Then the lowest value of the difference is found. This value is added to or subtracted from the differences so that the lowest value of the difference is zero. For example, if the lowest difference is $-55.62,55.62$ is added to all the differences (including the $110 \mathrm{kV}$ network).
8. The sets of standardized differences between the optimum and real transmission capacities are added within the same voltages. Three values are obtained for each voltage

$\sum^{\mathrm{i}} \Delta \varepsilon_{\mathrm{pin}}, \quad \sum^{\mathrm{i}} \Delta \varepsilon_{\mathrm{pis}}, \quad \Delta \varepsilon_{\mathrm{pi} 110}$

The total investment expenditure is divided accordingly, possibly after initial subtracting the sum intended to cover the cost of connecting new consumers to the $110 \mathrm{kV}$ voltage network.

$$
\begin{aligned}
N_{\mathrm{r} 110} & =\frac{N_{\mathrm{r}} \Delta \varepsilon_{\mathrm{p} 110}}{\sum^{\mathrm{i}} \Delta \varepsilon_{\mathrm{pin}}+\sum^{\mathrm{i}} \Delta \varepsilon_{\mathrm{piS}}+\Delta \varepsilon_{\mathrm{pi} 110}} \\
N_{\mathrm{rSN}} & =\frac{N_{\mathrm{r}} \sum \Delta \varepsilon_{\mathrm{pis}}}{\sum^{\mathrm{i}} \Delta \varepsilon_{\mathrm{pin}}+\sum^{\mathrm{i}} \Delta \varepsilon_{\mathrm{piS}}+\Delta \varepsilon_{\mathrm{pi} 110}} \\
N_{\mathrm{rnN}} & =\frac{N_{\mathrm{r}} \sum \Delta \varepsilon_{\mathrm{pin}}}{\sum^{\mathrm{i}} \Delta \varepsilon_{\mathrm{pin}}+\sum^{\mathrm{i}} \Delta \varepsilon_{\mathrm{piS}}+\Delta \varepsilon_{\mathrm{pi} 110}}
\end{aligned}
$$

The above are investment expenditures allocated to the networks of the respective voltages.

9. In the case of medium- and low-voltage networks the share of investment expenditure intended to cover the cost of new consumer connections is subtracted. In this way, for each network two qunatities are obtained

- Investment on new connections,

- Investment on the network development and modernization.

The new connection investment is

- For the low-voltage network

$$
N_{\mathrm{npn}}=0.35 \cdot N_{\mathrm{rnN}} \pm 10 \% \cdot 0.35 \cdot N_{\mathrm{rnN}}
$$

- For the medium-voltage network

$$
N_{\mathrm{nps}}=0.175 \cdot N_{\mathrm{rSN}} \pm 10 \% \cdot 0.175 \cdot N_{\mathrm{rSN}}
$$

The development and modernization investment is

- For the low-voltage network

$$
N_{\text {npn }}=0.65 \cdot N_{\mathrm{rnN}} \mp 10 \% \cdot 0.35 \cdot N_{\mathrm{rnN}}
$$

- For the medium-voltage network

$$
N_{\mathrm{nps}}=0.825 \cdot N_{\mathrm{rSN}} \mp 10 \% \cdot 0.175 \cdot N_{\mathrm{rSN}}
$$

10. The investment expenditures on the development and modernization are divided according to the criteria presented in Sect. 4, for each network. (Tables 5, 7).

11. The investment expenditures on the new consumer connections are divided among the area units on the basis of the real transmission capacity: 
- For the low-voltage network

$$
N_{\mathrm{pni}}=\frac{N_{\mathrm{npn}} \cdot \varepsilon_{\mathrm{pnNi}}}{\sum^{\mathrm{i}} \varepsilon_{\mathrm{pnNi}}}
$$

- For the medium-voltage network

$$
N_{\mathrm{pSi}}=\frac{N_{\mathrm{npn}} \cdot \varepsilon_{\mathrm{pSNi}}}{\sum^{\mathrm{i}} \varepsilon_{\mathrm{pSNi}}}
$$

12. Finally, the following are obtained: two quantities for every area unit: one for the low-voltage network, the other for the medium-voltage network representing the spending on the network development and modernization and two more quantities: one for the low-voltage network and the other for the medium-voltage network representing the spending on new consumer connections. Apart from those, a separate value is provided for the development and modernization of the $110 \mathrm{kV}$ network, and possibly new connections to it.

\section{Conclusions}

Basing the distribution of investment means on the difference between the real and the optimum transmission capacity of a network is a rational policy. It will be so even if some flaws occur in the calculations of the optimum values as long as the calculations for all the networks are based on the same cost coefficients.

Open Access This article is distributed under the terms of the Creative Commons Attribution Noncommercial License which permits any noncommercial use, distribution, and reproduction in any medium, provided the original author(s) and source are credited.

\section{References}

1. Bojar E, Bojar M, Pylak A (2010) Energia odnawialna w klastrze, Rynek Energii, nr. 1 (86)

2. Filipiak S (2010) Multiojective optimalization of Electric power distribution network post-fault configuration Rynek Energii nr 3 (88)
3. Horak J (1966) Zdolność przesyłowa sieci. Biuletyn Instytutu Energetyki luty 1966/1, 2. Energetyka 1

4. Pazio W (1994) Jak gospodarować finansami. Ekonomiczne podstawy biznesu, PWN Warszawa

5. Horak J, Gawlak A (1995) Nieciągłość zasilania odbiorców jako element rachunku optymalizacyjnego w rozdzielczych sieciach wiejskich. JUEE

6. Horak J, Gawlak A, Szkutnik J (1998) Sieć elektroenergetyczna jako zbiór elementów. P.Cz, Cz-wa

7. Gawlak A (1998) Wpływ nieciągłości zasilania i strat w transformatorach na optymalizacje sieci wiejskich niskiego napięcia. JUEE

8. Gawlak A (2010) Wpływ kryzysu gospodarczego na prognozę strat bilansowych, Rynek Energii, nr. 1 (86)

9. Horak J, Gawlak A (1996) Sieci elektryczne cz.3. Wydawnictwo $\mathrm{PCz}$, Częstochowa

10. Drury C (1995) Rachunek kosztów. PWN Warszawa

11. Gawlak A (2001) Rata odpisu rocznego w świetle prawa energetycznego. IV Konferencja Naukowo-Tech- niczna Metody i Systemy Komputerowe w Automatyce i Elektrotechnice. Częstochowa-Poraj

12. Horak J (1989) Straty sieciowe. Seria Monografie nr 8 Politechnika Częstochowska

13. Gawlak A (1994) Wpływ nieciągłości zasilania i strat w transformatorach na optymalizację sieci wiejskich niskiego napięcia. Praca doktorska, Częstochowa

14. Horak J, Gawlak A, Szkutnik J (2006) Optymalny podział środków inwestycyjnych na rozwój i modernizację sieci w spółce dystrybucyjnej. Wiadomości elektrotechniczne Warszawa I

15. Kocot H (2010) Nakłady inwestycyjne niezbędne do realizacji scenariuszy rozwojowych podsektora wytwarzania, Rynek Energii, nr. 2 (87) kwiecień

16. Korab R (2010) Zdolności przyłączeniowe krajowej sieci 400 i 220 kV, Rynek Energii, nr. 2 (87) kwiecień

17. Malko J (2010) Sieci inteligentne jako czynnik kształtowania sektora energii elektrycznej nr. 2 (87) kwiecień

18. Szkutnik J (2010) Smart meetering jako decydujące uwarunkowanie wdrożenia strategii DSM w Polsce, Rynek Energii, nr. 1 (86)

19. Witek B (2010) Rynkowo zorientowane elastyczne układy zasilania oparte na centrach sterowania jakością energii elektrycznej, Rynek Energii, nr. 2 (87) kwiecień

20. Zamasz K, Saługa Piotr (2010) Ocena efektywności ekonomicznej projektu rozbudowy mocy elektrociepłowni z wykorzystaniem analizy drzew decyzyjnych,Rynek Energii nr. 2 (87) kwiecień 